\title{
WORK ENVIRONMENT FACTORS AND WORK SUSTAINABILITY IN NORWEGIAN COOKS
}

\section{SINDRE RABBEN SVEDAHL ${ }^{1,2}$, KRISTIN SVENDSEN ${ }^{3}$, PÅL R. ROMUNDSTAD ${ }^{1,2}$, TORGUNN QVENILD ${ }^{2}$, TONJE STRØMHOLM², ODDFRID AAS ${ }^{2}$, and BJØRN HILT ${ }^{1,2}$}

${ }^{1}$ Norwegian University of Science and Technology, Trondheim, Norway

Department of Occupational Medicine, Department of Public Health and General Practice

${ }^{2}$ St. Olavs Hospital, Trondheim University Hospital, Trondheim, Norway

Department of Occupational Medicine

${ }^{3}$ Norwegian University of Science and Technology, Trondheim, Norway

Department of Industrial Economics and Technology Management

\begin{abstract}
Objectives: Cooks have increased morbidity and mortality. A high turnover has also been reported. We aimed to elucidate work environment and work sustainability in Norwegian cooks. Material and Methods: A questionnaire inquiring about working conditions and work participation was sent to 2082 cooks who had qualified from 1988 onwards. Of these, 894 responded. Time at work was analyzed with Kaplan-Meier plots and possible determinants for quitting work as a cook was analyzed with Cox regression. Results: The median time at work was 16.6 years. There were differences in sustainability between types of kitchens for both sexes $(\mathrm{p}=0.00)$. The median time in the profession was 9.2 years for the cooks in restaurants, while the cooks in institutions and canteens showed a substantially higher sustainability with $75.4 \%$ still at work after 10 years, and $57 \%$ still at work after 20 years in the profession. Of those still at work as a cook, 91.4\% reported a good or very good contentment, and the $67.4 \%$ who expected to stay in the profession the next 5 years frequently answered that excitement of cooking, the social working environment, and the creative features of cooking were reasons to continue. Musculoskeletal complaints were the most common health-related reason for leaving work as a cook, while working hours was the most common non-health-related reason. Conclusions: There are significant differences in work sustainability between the cooks in the different types of kitchens. The identified determinants for length of time in the occupation can be used for preventive purposes.
\end{abstract}

Key words:

Occupational health, Occupational exposure, Cooks, Work sustainability, Working hours, Musculoskeletal complaints

\section{INTRODUCTION}

Work-related health challenges have been reported among cooks [1-8]. Cooks face different physical risk factors including heavy lifting and repetitive movements, slippery floors, sharp objects, and hot equipment and substances [9,10].
An increased occurrence of musculoskeletal problems has been observed among cooks [3,11-13]. In accord with other studies we have previously shown that cooks are exposed to chemicals in cooking fumes such as polycyclic aromatic hydrocarbons $(\mathrm{PAH})$, heterocyclic amines, and

The study was supported with grant from the Work Environment Fund of the Confederation of Norwegian Enterprise through the Norwegian Hospitality Association. Project No. S-2832. Grant manager: Alf Åge Rønne, Director.

Received: August 28, 2014. Accepted: February 12, 2015.

Corresponding author: S. Rabben Svedahl, Norwegian University of Science and Technology (NTNU), Department of Occupational Medicine, Department of Public Health and General Practice, Harald Hardrådes gt 14, N-7006 Trondheim, Norway (e-mail: sindre.svedahl@ntnu.no). 
aldehydes [14-18]. Such exposures may be associated with rhinitis, respiratory disorders, and impaired lung function $[19,20]$. In a previous study we found an increased occurrence of respiratory symptoms in kitchen workers [4].

Forty percent of Norwegian cooks work irregular hours (6:00 p.m. - 6:00 a.m.) [21]. Shift-work has been found to reduce both length and quality of sleep, and is associated with several negative effects including mental, cardiovascular and reproductive health [22,23]. Long working hours are associated with sleep problems, mental disorders and coronary heart disease [24]. Psychosocial strain in the professional kitchen includes pace pressure [9,25] a high priority of customer service $[9,26,27]$ strict hierarchical systems and instances of workplace bullying [28].

It has been a common assumption that Norwegian cooks have a high occupational turnover with a mean duration of work as a cook of only 6-7 years after qualifying. Work-related health problems have been seen as an important reason for leaving the profession. In a previous study on Danish employees 35-59 years of age, work environment factors and self-rated health were independent predictors for remaining in work 5 years later [29]. In a recent cross sectional study on Swedish employees, fair organizational climate, high control, and low physical demands were associated with remaining in work, with < 14 days sick leave the current year [30]. The aim of our study was to elucidate work sustainability in cooks and to analyse if there is a connection between work environment factors and work sustainability.

\section{MATERIAL AND METHODS}

In Norway, education as a cook can follow two different paths, one as a restaurant cook and one as a cook for institutions. The administrations in 3 counties in the middle part of Norway provided us with names and personal identification number of 2082 subjects who had qualified as either of these in the years from 1988 through 2008. Early in 2010 they were asked to respond to a mailed questionnaire inquiring about working conditions at the place where they were working at present or had worked before quitting if they had ceased working as a cook. Of these subjects, 894 responded. Of the non-respondents, 155 had wrong and untraceable postal addresses, 11 had emigrated, 4 were deceased, and 4 gave other reasons for not participating. Consequently, the response rate was $49.6 \%$.

Table 1 shows background data for the cohort in relation to type of education, last or present place of work, and the type of kitchen with the longest held job for those who had worked $\geq 2$ years. In this context, the workplaces were divided into "Institution/canteen," "À la carte/ethnic," "Hotel," and "Others" which included all other types of kitchens such as pizza restaurants and takeaways.

The time of inclusion into the cohort was the date given by the authorities when each participant had qualified as a skilled cook, and the date of quitting was the month and year given by the participants who had ceased working as a cook. The year of inclusion in the cohort was near to evenly distributed between the 2 types of training. Those with training for institutions had a peak recruitment in the 5 years from 1997 to 2001 with 34.9\%, while the restaurant cooks had a peak recruitment a little later with $28.6 \%$ in the years 2001-2005 (Figure 1). For those who had not ceased, observation time was set to be through February 28, 2010.

As a basis for calculations of their longest held job, the participants were also inquired about the number of months they had previously worked in different types of kitchens. For those who had ceased working as a cook we asked for the reason, with the possibility to tag $\geq 1$ of the following options: musculoskeletal complaints, respiratory complaints, skin complaints, income, stress, inconvenient working hours, tight job market, or other reasons.

All data were stored and analysed with the IBM $^{\circledR}$ SPSS $^{\circledR}$ Statistics program version 20. Work sustainability was analysed with Kaplan-Meier survival analysis in relation to type of education, last or present place of work and type of kitchen with the longest held job. Differences between 


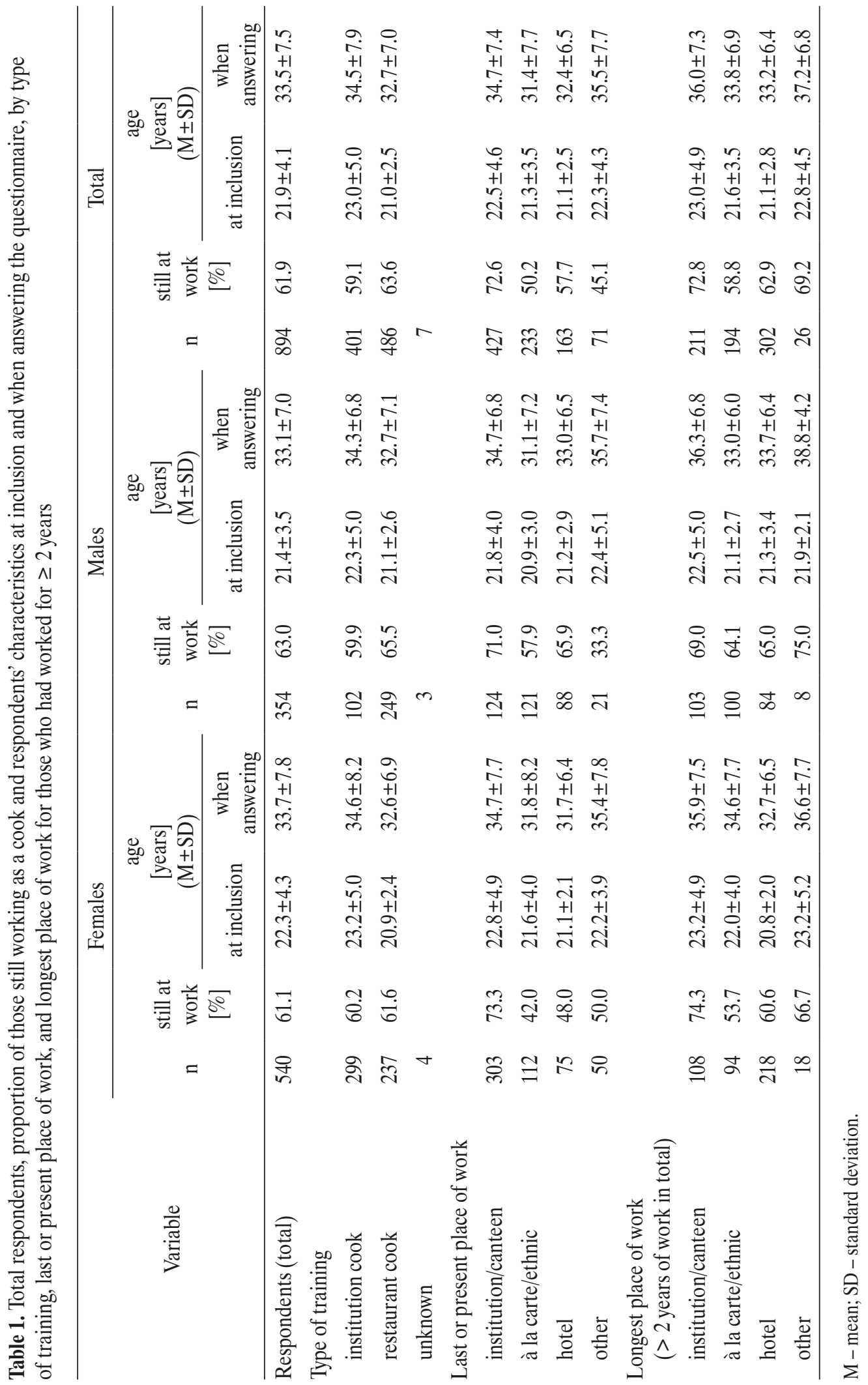




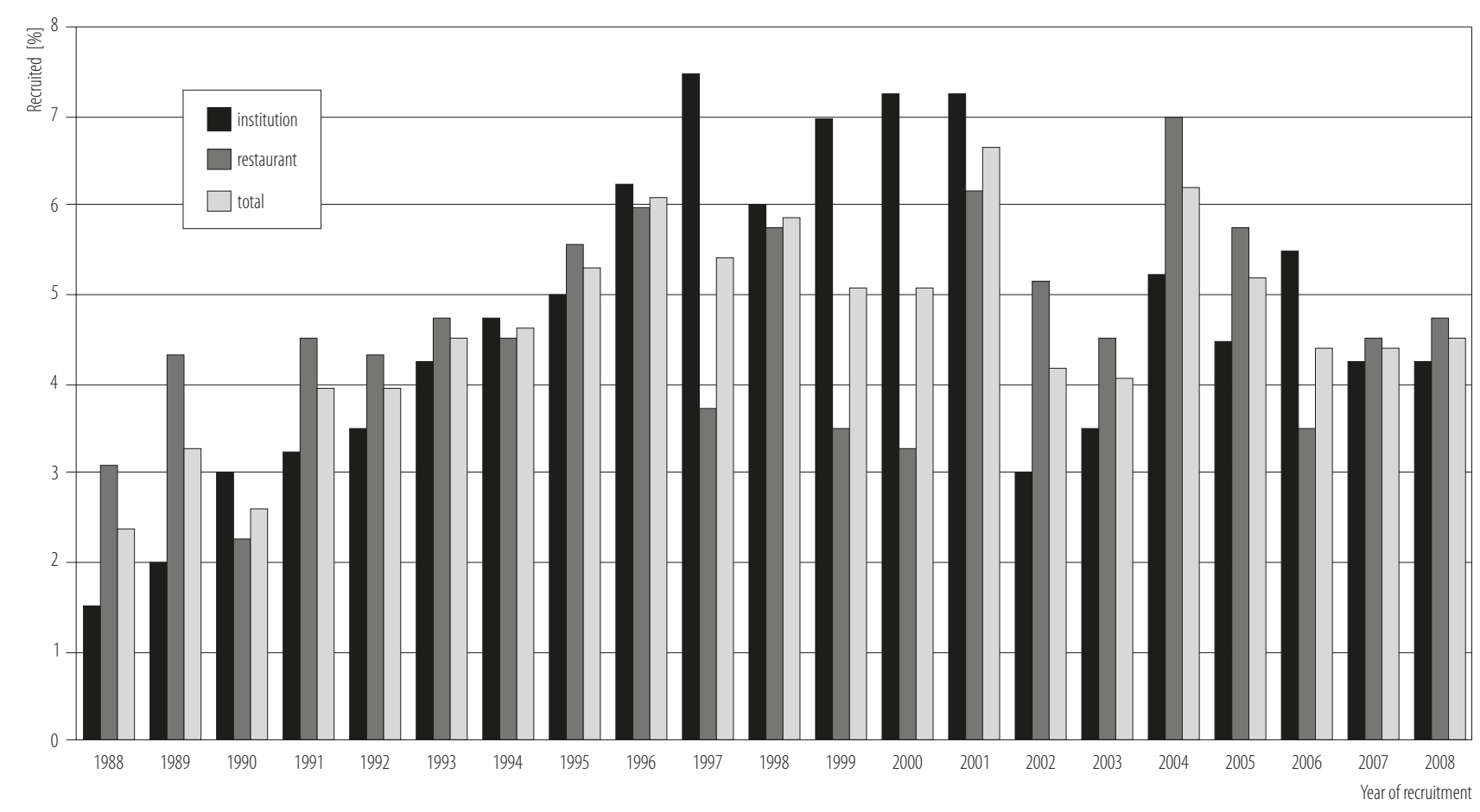

Fig. 1. Recruitment to the cohort 1988-2008 by specific type of training as a cook

groups were estimated by the Log Rank (Mantel Cox) test. In addition, we performed Cox regression analysis with adjustment for sex by the enter method in relation to last or present place of work, type of kitchen with the longest held job, shift work, working hours, type of food prepared, and some ergonomic factors. Other differences between groups were tested for statistical significance with a 2-tailed Pearson's Chi ${ }^{2}$ test.

We also asked the participants how pleased they were with their job as a cook in general, and from those who were still working we asked if they anticipated that they would still be working as a cook after 5 years. We examined this in relation to the type of kitchen where they were working at present. Reasons for anticipating quitting or staying were also explored with the possibility to tag $\geq 1$ options. The study protocol was reviewed and approved by the regional committee for medical research ethics in central Norway (approval No. 2008/2527). Signed informed consent was obtained from each subject.

\section{RESULTS}

There was a certain migration between the 2 educational groups in the study. Of 401 who were originally trained as a cook for institutions, $130(32.4 \%)$ had migrated and reported à la carte/ethnic, hotels or others as their last or present place of work. Of 486 originally trained for restaurants, $154(31.7 \%)$ reported institutions/canteens as their last or present place of work.

The median time in the profession for all participants was 16.5 years. Figure 2 shows a Kaplan-Meier plot of sustainability for men and women separately in relation to last or present place of work. There were statistically significant differences in sustainability between the groups for both males and females $(p=0.00)$. For both sexes together the median time in the profession was 9.2 years for the cooks in restaurants and 11.5 years for the cooks in hotels. The cooks in institutions and canteens showed a substantially higher sustainability with $75.4 \%$ still at work after 10 years, and $57 \%$ still at work in the profession after 20 years. 

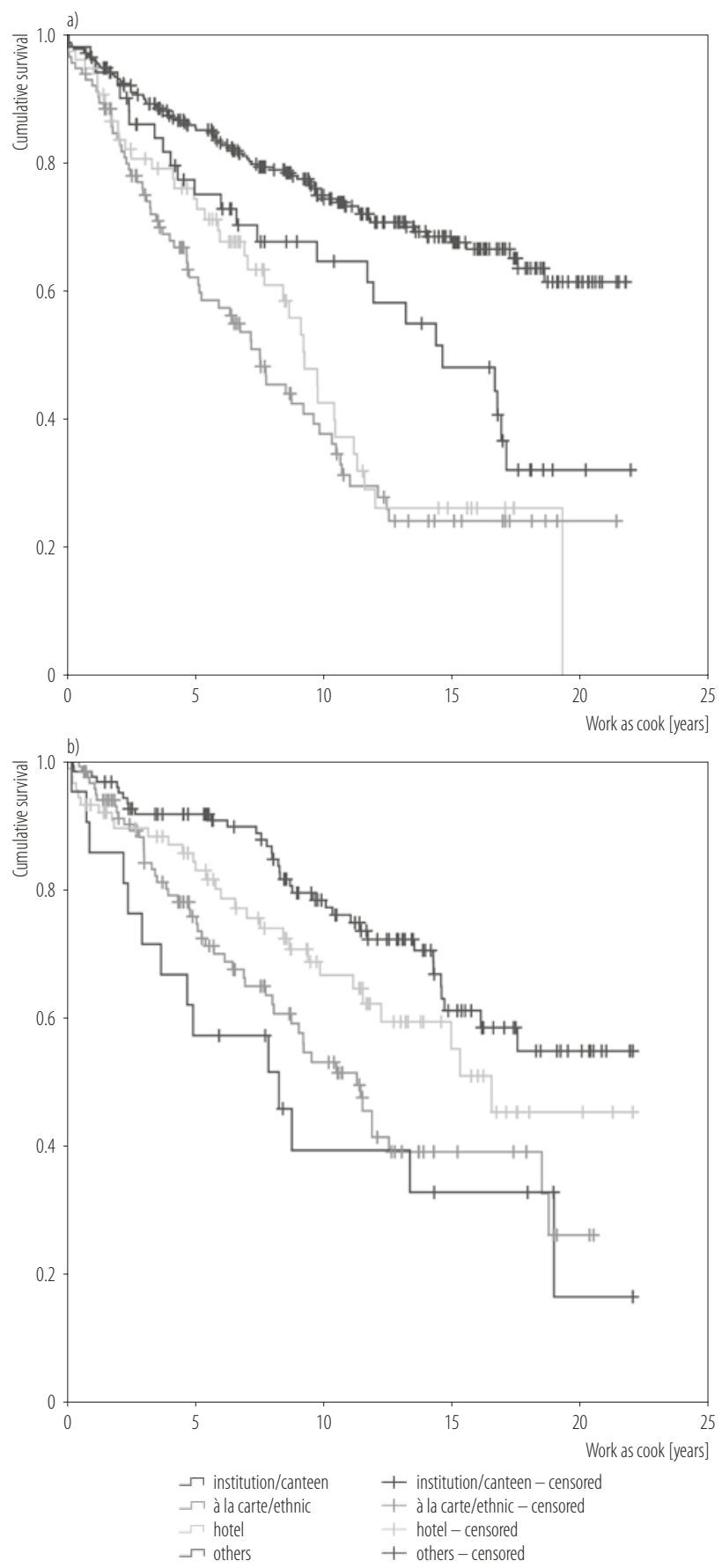

Fig. 2. Kaplan-Meier plots for sustainability as a cook for a) females and b) males separately in relation to last or present place of work as a cook

We also performed Kaplan-Meier analysis in relation to type of kitchen with "longest held job," (decided by calculating in what type of kitchen each subject had worked for the longest
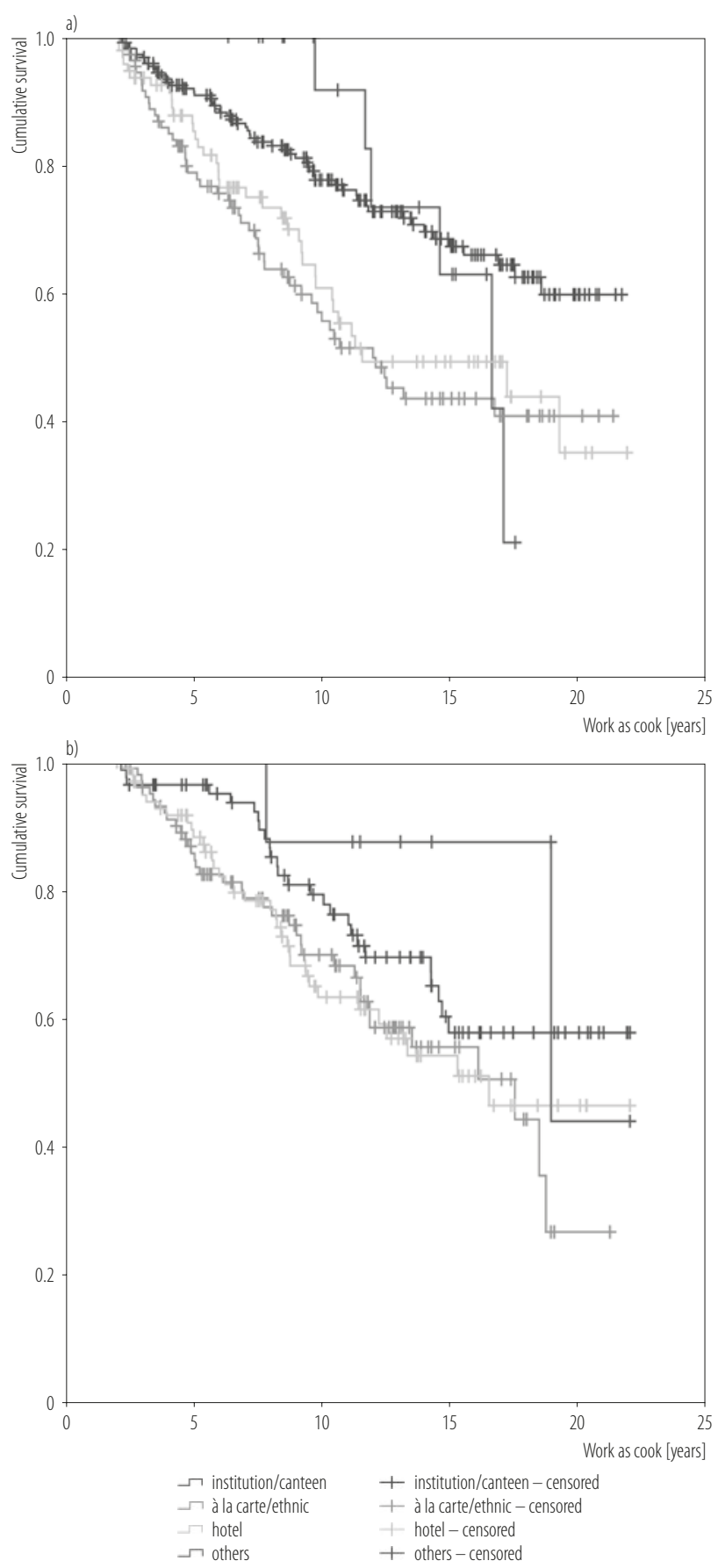

Fig. 3. Kaplan-Meier plots for sustainability as a cook for a) females and b) males in relation to type of kitchen with the longest held job as a cook

time). This analysis showed statistically significant differences in the sustainability between the different types of kitchens for females $(p=0.00)$, but not for males $(p=0.142)$ (Figure 3$)$. 

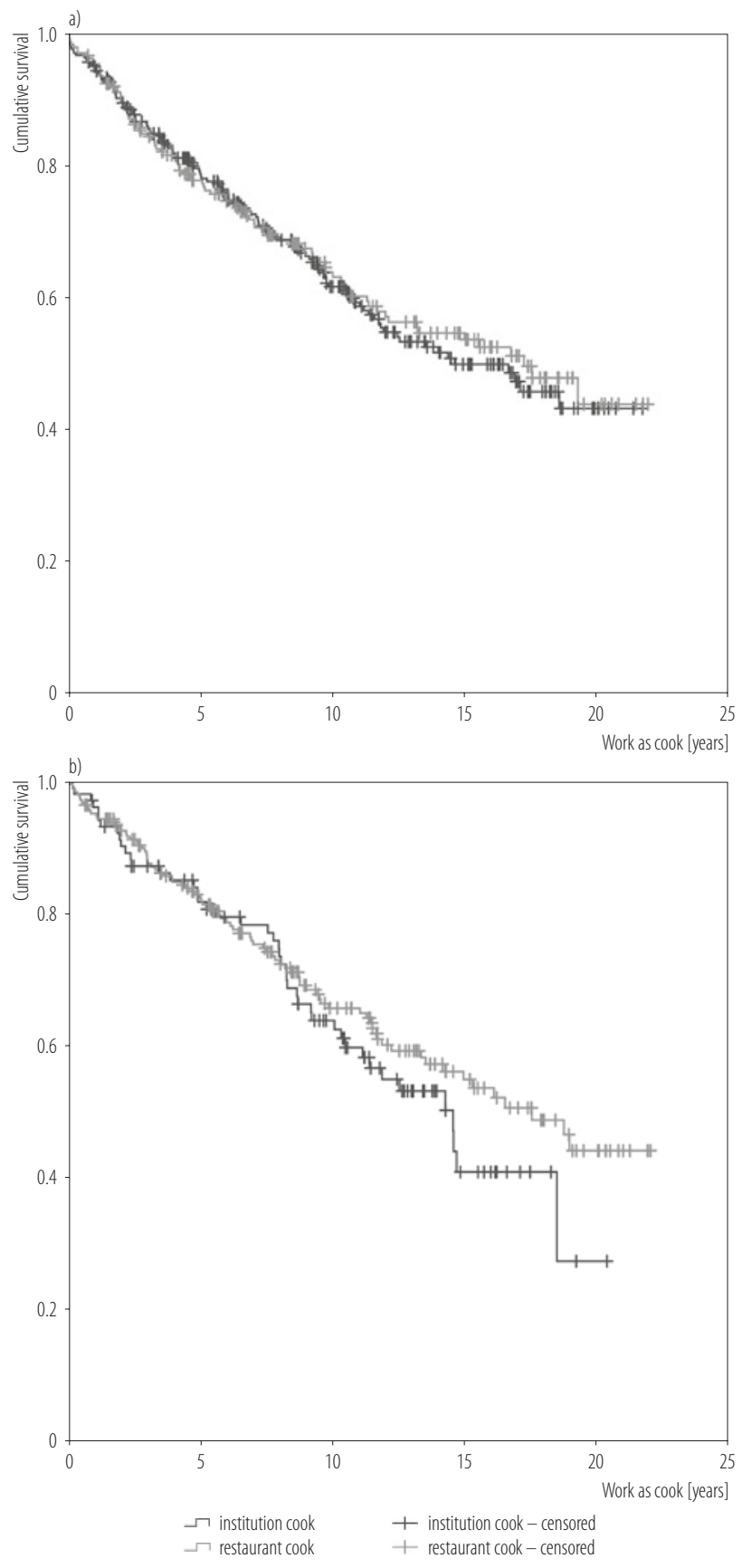

Fig. 4. Kaplan-Meier plots for sustainability as a cook for a) females and b) males in relation to type of training as a cook

In regard to type of education, the Kaplan-Meier plots were identical for females, while for the males the plot showed a better sustainability for restaurant cooks, without the difference being statistically significant $(p=0.3)$ (Figure 4).

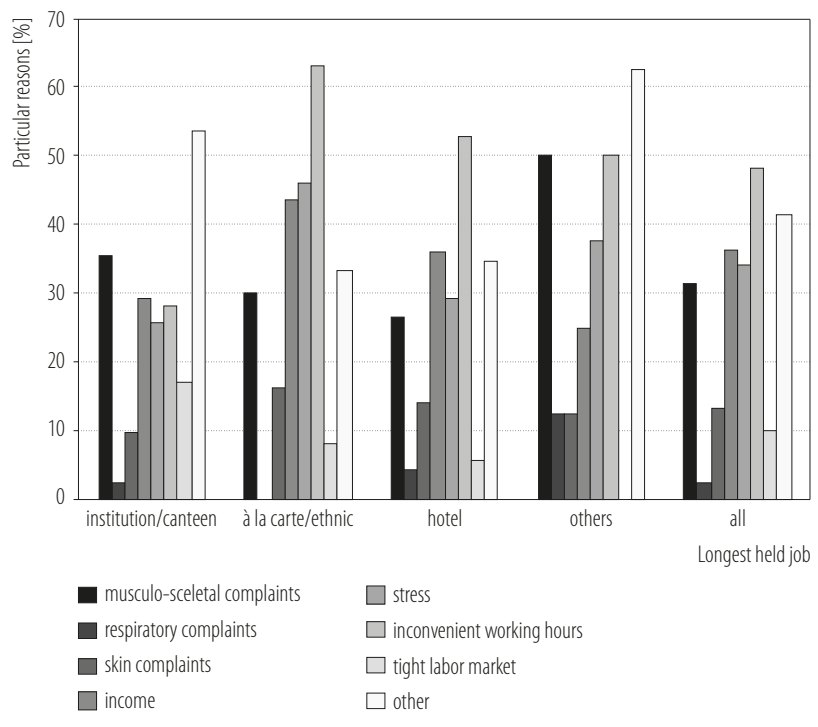

Fig. 5. Reasons given for quitting in relation to the longest held job in 249 who no longer worked as a cook

Seven subjects with unknown type of education were excluded from that analysis.

When looking at the reasons for having left work as a cook in relation to the longest held job in the 249 who had left the occupation, musculoskeletal complaints was the most common health-related reason with up to $50 \%$ in "other kitchens," while inconvenient working hours was the most common non-health-related reason with up to $63.2 \%$ in à la carte/ethnic and 52.8\% in hotels (Figure 5). Institutions made an exception here with income as the most frequent non-health-related specific reason for having ceased working as a cook. When comparing cooks with their longest held job in institutions and canteens with all the others, the only reasons given that differed in a statistically significant manner were fewer complaints of inconvenient working hours $(\mathrm{p}=0.0001)$ in the 1st group and that they more frequently reported anticipation of a tight job market $(\mathrm{p}=0.001)$.

In search for determinants for having quitted work as a cook (survival), a Cox regression analysis adjusting for sex and some other factors was performed. Table 2 presents hazard ratios for quitting as a cook determined 
by the regression analysis with the enter method and adjustment for sex in relation to last or present place of work, type of kitchen with the longest held job, shift work, working hours, type of food prepared, and some ergonomic factors. When comparing to institutions/canteens, those working in hotels or à la carte/ethnic restaurants showed increased hazard ratios in relation to both "last or present place of work" and "longest held type of kitchen."
Other determinants that showed statistically significant differences were related to shift work and weekly working hours. For the latter, those with working hours of $>50 \mathrm{~h}$ a week were shown to be less prone to quitting. Ergonomic factors like physically heavy work and monotonous and repetitive work did not turn out to be a determinant for quitting.

The 561 respondents who answered that they were still working as a cook, were asked about their

Table 2. Cox regression analysis in relation to last or present place of work, longest place of work for those with $>2$ years at work in total, and some specific work characteristics

\begin{tabular}{|c|c|c|}
\hline Variable & $\begin{array}{c}\text { Respondents } \\
(\mathrm{N}=894) \\
{[\mathrm{n}]}\end{array}$ & Hazard ratio \\
\hline \multicolumn{3}{|l|}{ Last or present workplace } \\
\hline institution/canteen & 233 & 1.000 \\
\hline à la carte/ethnic & 163 & $2.970^{* *}$ \\
\hline hotel & 427 & $2.200^{* *}$ \\
\hline other & 71 & $2.200^{* *}$ \\
\hline \multicolumn{3}{|c|}{ Longest place of work ( $>2$ years of work in total) } \\
\hline institution/canteen & 211 & 1.000 \\
\hline à la carte/ethnic & 194 & $1.940^{* *}$ \\
\hline hotel & 302 & $1.780^{* *}$ \\
\hline other & 26 & 0.928 \\
\hline \multicolumn{3}{|l|}{ Shift work (info from 874 respondents) } \\
\hline only daytime & 388 & 1.000 \\
\hline mostly late & 56 & $3.340^{* *}$ \\
\hline 2 shift & 321 & $1.810^{* *}$ \\
\hline other schedules & 109 & 1.120 \\
\hline \multicolumn{3}{|c|}{ Weekly working time (info from 870 respondents) } \\
\hline$<20 \mathrm{~h}$ & 36 & 1.050 \\
\hline 20-39 h ("normal") & 522 & 1.000 \\
\hline $40-49 \mathrm{~h}$ & 214 & $1.690^{* *}$ \\
\hline$>50 \mathrm{~h}$ & 98 & $0.600^{*}$ \\
\hline \multicolumn{3}{|l|}{ What kind of food is/was usually prepared } \\
\hline about same amount of warm and cold & 596 & 1.000 \\
\hline mostly cold & 43 & $1.580^{* *}$ \\
\hline mostly warm & 229 & 0.726 \\
\hline
\end{tabular}


Table 2. Cox regression analysis in relation to last or present place of work, longest place of work for those with $>2$ years at work in total, and some specific work characteristics - cont.

\begin{tabular}{lcc}
\hline \multicolumn{1}{c}{ Variable } & $\begin{array}{c}\text { Respondents } \\
(\mathrm{N}=894) \\
{[\mathrm{n}]}\end{array}$ & Hazard ratio \\
\hline To what extent is/was your work heavy & 62 & 1.000 \\
$\quad$ little & 408 & 1.020 \\
$<1 / 2$ of the time & 402 & 0.880 \\
$>1 / 2$ of the time & & \\
To what extent is/was your work monotonous and repetitive & 85 & 1.000 \\
small & 297 & 1.370 \\
moderate & 491 & 1.280 \\
large & & \\
\hline
\end{tabular}

$* \mathrm{p}<0.05 ; * \mathrm{p}<0.000$

general contentment with their work as a cook, and asked if they anticipated that they would still be working as a cook in 5 years time. Of those still working as a cook, $91.5 \%$ reported a very good or good contentment with their work as a cook. When stratifying the answers in regard to present work place, there were only small differences between the particular groups in regard to the general contentment, while there was a statistically significantly greater proportion of cooks in institutions/ canteens $(75.1 \%)$ compared to cooks in other workplaces $(57.4 \%)$ who thought that they would continue as a cook after 5 years $(\mathrm{p}=0.0001)($ Table 3$)$.
Out of those still working as a cook, 180 subjects (32.1\%) stated that they thought they would not be working as a cook in 5 years. Among them, the reasons most frequently given for this were: musculoskeletal complaints $(46.1 \%)$, income $(52.2 \%)$, stress $(52.2 \%)$ and their working hours $(50.6 \%)$. In Figure 6 we have presented these reasons stratified by current workplace. Here the only statistically significant finding was that, compared to cooks in all other workplaces, the cooks in institutions/canteens less frequently reported "working hours" and "stress" as reasons to anticipating quitting, $(\mathrm{p}=0.0001)$.

Table 3. Work contentment and anticipations among the respondents still working as cooks

\begin{tabular}{lccccc}
\hline \multirow{2}{*}{$\begin{array}{c}\text { Present place } \\
\text { of work }\end{array}$} & \multicolumn{5}{c}{$\begin{array}{c}\text { Respondents } \\
\text { (N = 551) }\end{array}$} \\
\cline { 2 - 6 } & \begin{tabular}{c} 
share anticipation to \\
be at work in 5 years \\
\cline { 2 - 6 }
\end{tabular} & \multicolumn{4}{c}{$\begin{array}{c}\text { general contentment with work } \\
{[\%]}\end{array}$} \\
\cline { 2 - 6 } Institution/canteen & $232(75.1)$ & very good & good & not too good & poor \\
À la carte/ethnic & $61(52.1)$ & 30.3 & 52.6 & 6.2 & 1.0 \\
Hotel & $60(63.8)$ & 35.1 & 48.3 & 13.8 & 0.9 \\
Other & $18(58.1)$ & 45.2 & 58.1 & 6.5 & 0.0 \\
All & $371(67.3)$ & 39.1 & 48.4 & 3.2 & 3.2 \\
\hline
\end{tabular}




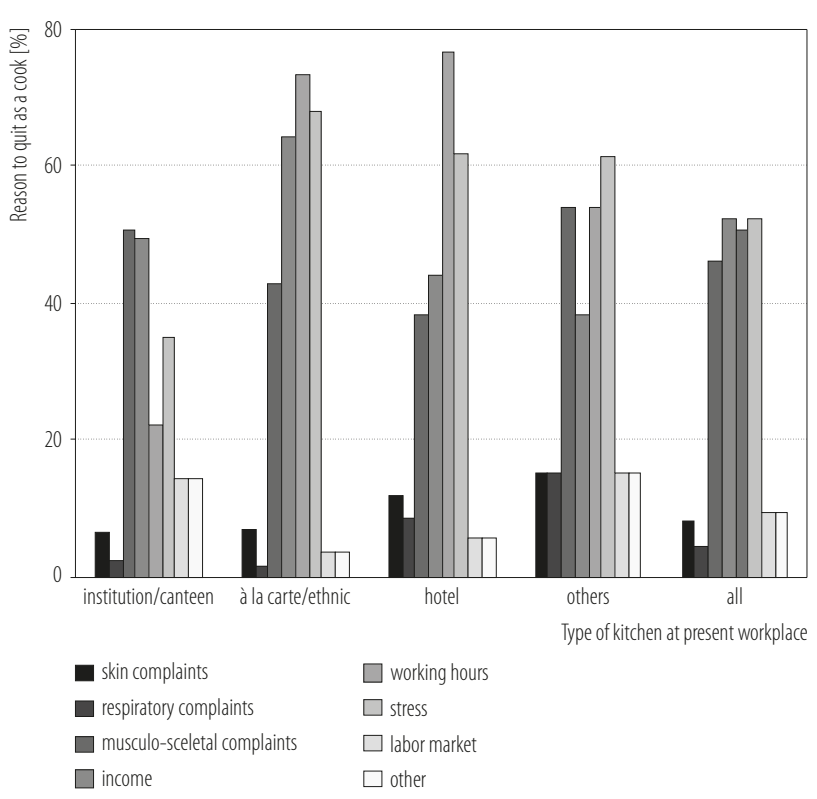

Fig. 6. Reasons given for possibly quitting as a cook during the next 5 years by 180 cooks who anticipated that they would not be working as a cook in 5 years time

For the 371 who thought they would stay working as a cook, the most common reasons for staying were that it is exciting to prepare food (63.9\%), that cooking is creative work $(52 \%)$, and a good social working environment (64.4\%) (Figure 7). Compared to cooks in institutions/ canteens, a greater proportion of cooks in other workplaces found it more exciting to prepare food $(p=0.004)$ and, in particular for cooks working in à la carte restaurants and hotels, that cooking is a creative job $(\mathrm{p}=0.0001)$. Cooks in institutions/canteens more frequently found that their working hours was a reason to continue as a cook $(\mathrm{p}=0.0001)$.

\section{DISCUSSION}

This study shows by Kaplan-Meier plots that there are differences in work sustainability in cooks between the different types of kitchens, both in terms of last and present workplace for both sexes, and in terms of longest place of work for females. From the accessible literature, it seems well established that work environment factors in general have impact on health, work-wellbeing, and

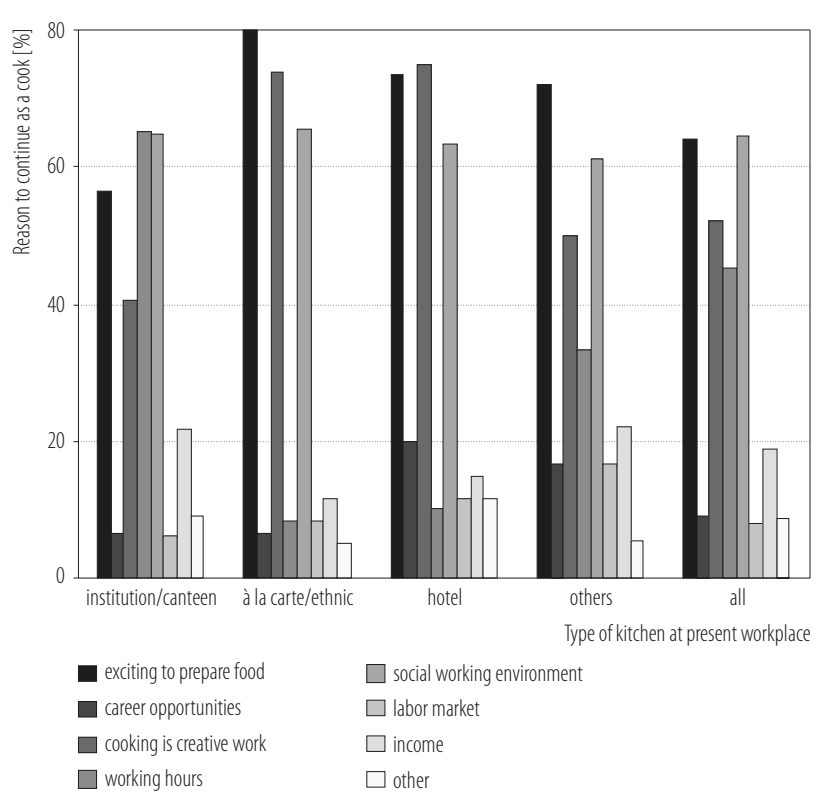

Fig. 7. Reasons given for wanting to stay as a cook by 371 cooks who anticipated that they would still be working as a cook in 5 years time

sickness absence, but there have been few publications on determinants of work sustainability apart from the previous study on Danish workers showing that work environment factors and self-rated health were independent predictors of remaining in work 5 years later [29]. Though not directly comparable, we find it reasonable to assume that the shown difference in work sustainability between the different types of kitchens in our cohort is determined by differences in work environment factors.

In à la carte restaurants the activities are directed by the current customer orders, usually with a fixed maximum delivery time, which may implicate an extremely high workload during the busiest periods. This may obstruct ergonomic work methods as well as hamper the possibility to take breaks when needed. À la carte restaurants usually have their busiest hours during late evenings, which also implicate a deviation from normal working hours. In canteens and institutions, it is often possible to plan the work in advance with a more even workload throughout the day, including the possibility to take breaks when needed. 
It is known that shift work, long or irregular working hours can have negative impact on health [22-24]. In our Cox regression analysis, specific work-related factors like shift work and working hours showed a significant impact on work sustainability. Working mostly late shifts was the specific work environment factor that implicated the highest risk of quitting, while those working in a "two-shift" schedule also showed higher risk of quitting than those working only daytime.

Since $55.6 \%$ of the cooks in our cohort declared working shift work, and earlier studies have shown that $40 \%$ of the cooks in Norway work irregular hours [21], this may well be a major determinant of both health and sustainability in cooks. Such implications on the cooks' work sustainability are also supported by the reasons given by the respondents for anticipating to stay or to quit the profession. Convenient working hours was frequently stated as a reason to continue as a cook in institutions and canteens, while inconvenient working hours was frequently stated as a reason for quitting among those working in other types of kitchens. And, even though the cooks who were working in institutions and canteens less frequently stated that creative features of cooking was a reason to stay in the profession, a greater proportion of them (75.1\%), compared to cooks in other workplaces (57.4\%), thought that they would continue as a cook after 5 years.

In our study, the most frequently stated health-related reason for leaving the occupation was musculoskeletal complaints. Previous studies have shown that known risk factors for musculoskeletal disorders such as repetitive movements, lifting, and stress are common amongst professional cooks $[9,10]$. Previous studies have also reported an increased occurrence of musculoskeletal disorders in kitchen workers [3,11-13], but apart from one cross-sectional study in restaurant workers from Taiwan, the social consequences have mostly not been investigated. In the study from Taiwan it was found that the increased prevalence of work-related musculoskeletal disorders probably did not affect job performance or daily living [13]. This is in contrast to our finding with a significant effect on work sustainability due to musculoskeletal complaints. This may, however, be explained by methodological differences between the 2 studies, or reflect cultural and socioeconomic differences between Norway and Taiwan. As the recruitment to our study was based on the registers made at the time of qualifying as cooks (1988-2008), and information was collected retrospectively, we consider it to have a historic prospective approach. In contrast to a cross-sectional study, the relatively long follow up in our study might have reduced selection bias and strengthened the possibility to elucidate health-related social consequences. Having to end a professional career due to workrelated health complaints is a serious problem both for the individual and the society. The fact that data was collected at the end of the observation period with a mailed questionnaire can, however, have introduced information bias, in particular when inquiring about complaints and consequences simultaneously [31].

As cooking fumes contain known airway irritants [1418], the low rate of respiratory complaints as a reason for quitting was unexpected. We have previously shown that cooks have an increased prevalence of both dyspnea and other respiratory symptoms [4]. This may still be the case in the present cohort, but apparently the cooks did not quit because of such complaints. Another explanation could also be the relatively young age of the cohort, and the picture might have looked differently in a group of older cooks.

The low response rate of just below $50 \%$ in our study could have introduced another source of selection bias. We did, therefore, perform a non-responder inquiry by telephone calls to non-responders asking them only if they were still active as a cook. There were $50 \%$ of the 46 non-responders that were reached who were still in the profession, while the corresponding figure for the original responders was $61.9 \%$. With this small difference, there is little 
reason to assume that the low participation rate biased the results decisively.

There were no statistically significant differences in sustainability between cooks originally trained for restaurants and cooks originally trained for institutions. We did, however, observe that there had been a considerable migration from type of education to current place of work, and this was, to our surprise, similar in both directions. We expected that those originally trained for restaurants would show a greater migration towards work in institutions and canteens in order to seek more favourable working hours and less stress. There might, however, still be different reasons for migrating, such as to seek excitement in the restaurants and to seek more quiet work, and more favourable working hours in the institutions. Thus, the migration pattern may have diluted possible differences in sustainability between the different types of educations. Anyway, it seems that place of work is more important than type of education as a determinant of work sustainability.

Work environment factors may influence migration and work sustainability differently in males and females. Females are often expected to take responsibility for family and children and might therefore tend to leave work places with shift work, and long working hours earlier in their career than males. Such differences in migration between jobs may also explain why differences in sustainability in relation to the longest held job was statistically significant for female cooks, but not for male.

With a median sustainability in the profession 14-18 years, the results showed that Norwegian cooks stay longer in their profession than the 6-7 years previously assumed. We do, however, not know the significance of this compared to other occupations. In our view, having a median time in the occupation of 16.5 years in relation to a maximum observation time of 21 years can be considered as acceptable. It should also be recognised that the relatively young cooks who participated in our study, independent of their place of work, seem to have a high contentment with their work as a cook, and that the majority of those who anticipate to stay in the occupation think of their work as both exciting and creative. An advice to employers of cooks who want to stabilize their workforce should be to care for the working environment in general, to intervene with work organization and working hours, and sustain the features that have been shown to be appreciated by cooks.

\section{CONCLUSIONS}

There are significant differences in work sustainability between the cooks in the different types of kitchens, and the work sustainability is determined both by work- and health-related factors, the most important being working hours and musculoskeletal complaints.

\section{ACKNOWLEDGMENTS}

We thank the participants of the study for their friendly willingness to respond to lengthy questionnaires. Patricia Flor is acknowledged for her linguistic help in preparing the manuscript.

\section{REFERENCES}

1. Johnson NJ, Sorlie PD, Backlund E. The impact of specific occupation on mortality in the U.S. National Longitudinal Mortality Study. Demography. 1999;36(3):355-67, http:// dx.doi.org/10.2307/2648058.

2. Kjaerheim K, Martinsen JI, Lynge E, Gunnarsdottir HK, Sparen P, Tryggvadottir L, et al. Effects of occupation on risks of avoidable cancers in the Nordic countries. Eur J Cancer. 2010;46(14):2545-54, http://dx.doi.org/10.1016/ j.ejca.2010.07.038.

3. Shiue HS, Lu CW, Chen CJ, Shih TS, Wu SC, Yang CY, et al. Musculoskeletal disorder among 52,261 Chinese restaurant cooks cohort: Result from the National Health Insurance Data. J Occup Health. 2008;50(2):163-8, http://dx.doi. org/10.1539/joh.L7093.

4. Svendsen K, Sjaastad AK, Sivertsen I. Respiratory symptoms in kitchen workers. Am J Ind Med. 2003;43(4):436-9, http:// dx.doi.org/10.1002/ajim.10197. 
5. Foppa I, Minder CE. Oral, pharyngeal and laryngeal cancer as a cause of death among Swiss cooks. Scand J Work Environ Health. 1992;18(5):287-92, http://dx.doi.org/10.5271/ sjweh.1575.

6. Sjogren B, Barlow L, Weiner J. Ischemic heart disease among cooks, cold buffet managers, kitchen assistants, and wait staff. Scand J Work Environ Health. 2009; Suppl 7:24-9.

7. Borgan J-K. [Occupation and mortality 1960-2000]. Oslo: Statistics Norway; 2009. Norwegian.

8. Bigert C, Lonn M, Feychting M, Sjogren B, Lewne M, Gustavsson P. Incidence of myocardial infarction among cooks and other restaurant workers in Sweden 1987-2005. Scand J Work Environ Health. 2013;39(2):204-11, http:// dx.doi.org/10.5271/sjweh.3331.

9. Tsai JH-C, Salazar MK. Occupational hazards and risks faced by Chinese immigrant restaurant workers. Fam Community Health. 2007;30 Suppl 2:S71-9, http://dx.doi. org/10.1097/01.FCH.0000264882.73440.20.

10. Mardis AL, Pratt SG. Nonfatal injuries to young workers in the retail trades and services industries in 1998. J Occup Environ Med. 2003;45(3):316-23, http://dx.doi.org/10.1097/01. jom.0000052964.43131.8a.

11. Ono Y, Shimaoka M, Hiruta S, Takeuchi Y. Low back pain among cooks in nursery schools. Ind Health. 1997;35(2): 194-201, http://dx.doi.org/10.2486/indhealth.35.194.

12. Haukka E, Leino-Arjas P, Solovieva S, Ranta R, Viikari-Juntura E, Riihimaki H. Co-occurrence of musculoskeletal pain among female kitchen workers. Int Arch Occup Environ Health. 2006;80(2):141-8, http://dx.doi.org/10.1007/s00420006-0113-8.

13. Chyuan JYA, Du CL, Yeh WY, Li CY. Musculoskeletal disorders in hotel restaurant workers. Occup Med. 2004; 54(1):55-7, http://dx.doi.org/10.1093/occmed/kqg108.

14. Thiebaud HP, Knize MG, Kuzmicky PA, Hsieh DP, Felton JS. Airborne mutagens produced by frying beef, pork and a soy-based food. Food Chem Toxicol. 1995;33(10):8218, http://dx.doi.org/10.1016/0278-6915(95)00057-9.
15. Chiang TA, Wu PF, Ko YC. Identification of carcinogens in cooking oil fumes. Environ Res. 1999;81(1):18-22, http:// dx.doi.org/10.1006/enrs.1998.3876.

16. Sjaastad AK, Jorgensen RB, Svendsen K. Exposure to polycyclic aromatic hydrocarbons (PAHs), mutagenic aldehydes and particulate matter during pan frying of beefsteak. Occup Environ Med. 2010;67(4):228-32, http://dx.doi.org/10.1136/ oem.2009.046144.

17. Sjaastad AK, Svendsen K. Exposure to mutagenic aldehydes and particulate matter during panfrying of beefsteak with margarine, rapeseed oil, olive oil or soybean oil. Ann Occup Hyg. 2008;52(8):739-45, http://dx.doi.org/10.1093/annhyg/ men060.

18. Vainiotalo S, Matveinen K. Cooking fumes as a hygienic problem in the food and catering industries. Am Ind Hyg Assoc J. 1993;54(7):376-82, http://dx.doi. org/10.1080/15298669391354838.

19. Ng TP, Hui KP, Tan WC. Respiratory symptoms and lung function effects of domestic exposure to tobacco smoke and cooking by gas in non-smoking women in Singapore. J Epidemiol Community Health. 1993;47(6):454-8, http://dx.doi. org/10.1136/jech.47.6.454.

20. Ng TP, Tan WC. Epidemiology of allergic rhinitis and its associated risk factors in Singapore. Int J Epidemiol. 1994;23(3):553-8, http://dx.doi.org/10.1093/ije/23.3.553.

21. Aagestad C, Tynes T, Sterud T, Løvseth E, Gravseth H, Eiken T, et al. [Facts book on work environment and health]. Oslo: Statens Arbeidsmiljøinstitutt; 2011. Norwegian.

22. Harrington JM. Health effects of shift work and extended hours of work. Occup Environ Med. 2001;58(1):68-72, http://dx.doi.org/10.1136/oem.58.1.68.

23. Rajaratnam SM, Arendt J. Health in a 24-h society. Lancet. 2001;358(9286):999-1005, http://dx.doi.org/10.1016/S01 40-6736(01)06108-6.

24. Bannai A, Tamakoshi A. The association between long working hours and health: A systematic review of epidemiological evidence. Scand J Work Environ Health. 2014;40(1):5-18, http://dx.doi.org/10.5271/sjweh.3388. 
25. Evensen CT, Schulman MD, Runyan CW, Zakocs RC, Dunn KA. The downside of adolescent employment: Hazards and injuries among working teens in North Carolina. J Adolesc. 2000;23(5):545-60, http://dx.doi.org/10.1006/ jado.2000.0342.

26. De Castro AB, Curbow B, Agnew J, Haythornthwaite JA, Fitzgerald ST. Measuring emotional labor among young workers: Refinement of the Emotions at Work Scale. AAOHN J. 2006;54(5):201-9.

27. West C, de Castro AB, Fitzgerald ST. The youth work force: Unique occupational health considerations and challenges. AAOHN J. 2005;53(7):297-305.

28. Mathisen GE, Einarsen S, Mykletun R. The occurrences and correlates of bullying and harassment in the restaurant sector. Scand J Psychol. 2008;49(1):59-68, http://dx.doi. org/10.1111/j.1467-9450.2007.00602.x.

29. Lund T, Borg V. Work environment and self-rated health as predictors of remaining in work 5 years later among Danish employees 35-59 years of age. Exp Aging Res. 1999;25 (4):429-34, http://dx.doi.org/10.1080/036107399243904.

30. Holmgren K, Love J, Mardby AC, Hensing G. Remain in work - What work-related factors are associated with sustainable work attendance: A general population-based study of women and men. J Occup Environ Med. 2014;56(3):23542, http://dx.doi.org/10.1097/JOM.0000000000000096.

31. Kristensen P. [Bias from dependent errors in observational studies]. Tidsskr Nor Laegeforen. 2005;125(2):173-5. Norwegian.

This work is available in Open Access model and licensed under a Creative Commons Attribution-NonCommercial 3.0 Poland License - http://creativecommons.org/ licenses/by-nc/3.0/pl/deed.en. 